\title{
The Open Innovation Journey in Emerging Economies: An Analysis of the Brazilian Aerospace Industry
}

\author{
Fabiano Armellini ${ }^{1}$, Paulo Carlos Kaminski², Catherine Beaudry ${ }^{1}$
}

\begin{abstract}
Open innovation is the systematic integration of collaborative, sourcing and revealing practices into a firm's business strategy. Its implementation does not happen at once, but through a journey. This paper investigates this subject in an emergent economy context, the Brazilian aerospace industry, presenting the critical analysis of a questionnaire-based survey performed by means of personal in-company interviews in 22 firms. It comprises a wide range of practices associated with open innovation, connected to a conceptual model. We find open innovation elements in the sample, with no open business strategy behind them, though. Deficiencies regarding funding, R\&D maturity and intellectual property protection prevent the cluster from being fully open innovator. Nevertheless, the culture company in the sample is very prone towards openness. From that, we conclude that open innovation in the cluster is still "unfreezing", but with great potential to emerge, once these problems are solved.
\end{abstract}

KEYWORDS: Open innovation, Aerospace Industry, Brazil, Innovation management.

\section{INTRODUCTION}

This work is about the applicability and importance of open innovation to the Brazilian aerospace industry.

Open innovation is a term coined by Chesbrough (2003a) to designate a new mindset within industrial organization in which companies make use of "purposive inflows and outflows of knowledge to accelerate internal innovation, and expand the markets for external use of innovation, respectively" (Chesbrough, 2006).

The subject of collaboration, networking and use of external sources for research and development (R\&D) is not a novelty in the academic and specialized literature about innovation management. Freeman (1991), in a review paper in the early 1990's, has shown evidence that the use of formal and informal R\&D networks and other kinds of collaborative arrangements are in order since before World War II. Freeman also states that the growth of structured networks of innovators, claimed by Chesbrough (2003b) to be at the root of the open innovation era, dates from the 1980's. Also within new product development (NPD) literature, review papers on the subject prior to the rise of open innovation (e.g. Brown and Eisenhardt, 1995; Liyanage et al., 1999; Krishnan and Ulrich, 2001) identify a clear outward tendency in their time.

In spite of all that, the coining of the term "open innovation" has brought to the literature a binding perspective on a number of existing practices, and the necessity to structure such practices into firms' strategies. According to the OECD (2008), the novelty of the open innovation approach lies on the systematic

\footnotetext{
三 1.Polytechnique Montréal - Montréal - Canada 2.Universidade de São Paulo - São Paulo/SP - Brazil

三 Author for correspondence: Fabiano Armellini | Department of Mathematical and Industrial Engineering - Polytechnique Montréal | 2900 Boulevard Edouard-Montpetit-Montréal/QC H3T 1J4 | Canada | Email: fabiano.armellini@polymtl.ca

Received: 08/28/2014 | Accepted: 10/28/2014
} 
integration of such practices into firms' strategy, as well as on the exploitation of the outbound (inside-out) process by firms.

It is evident that the adoption of open innovation is different from firm to firm, and from industry to industry. So it should be, since the "optimum" level of openness depends on variables such as technology intensity, value chain position, and product development average lead times, to name a few (Chesbrough, 2003b; West et al., 2006). According to Chesbrough and Appleyard (2007), a good open business strategy "balances the tenets of traditional business strategy with the promise of open innovation". In other words, it is about the decision of what shall and what shall not be disclosed.

The adoption of open innovation does not happen at once, though. Enkel et al. (2011), for instance, developed a maturity level framework, which identifies five stages of adoption of open innovation: (1) Initial/arbitrary; (2) Repeatable; (3) Defined; (4) Managed; and (5) Optimizing.

Chiaroni et al. (2011), in their turn, classify the level of adoption of open innovation by means of a three-axed framework, which they name "the open innovation journey".

In the first axe, the process of adoption of open innovation is split into three stages: the first is the "unfreezing" stage, which implies in establishment of a sense of urgency of change and a cultural shift towards openness, although not yet put in practice. The second, called the "moving" stage, concerns the actual implementation of change through the establishment of new procedures and patterns of behavior consistent to the new vision derived from the cultural shift. Finally, the third one is the "institutionalizing" stage, which the company achieves when open innovation is incorporated to its formal procedures and internal business process maps, with its own metrics and subjected to continuous improvement procedures.

The second axe is with respect to the direction of openness, and adopts the terminology of Enkel et al. (2009): outside-in and inside-out, the first usually preceding the latter. The third axe regards the structuring of managerial levers for open innovation, namely:

- Networking;

- Organizational structures;

- Evaluation processes; and

- Knowledge management systems.

From these two papers (Enkel et al., 2011; Chiaroni et al., 2011), one realizes that it is not just a matter of determining whether open innovation is adopted or not, but also of establishing at which step one sits. This question can also be posed at the industry level.

Another issue identified in the emerging open innovation literature is that although the concept has been presented as a general trend (sometimes even as a paradigm change), what is observed in practice is that open innovation publications are clustered into a few "open-dominated industry segments" (Chesbrough and Appleyard, 2007), where the evidences of openness are more clearly found. Another limitation is that most of the studies published so far analyze open innovation in the context of developed economies (especially the U.S. and the European innovation systems) as first noticed by West et al. (2006), which persists to date.

That being said, this paper has, therefore, a double-edged purpose: the first one is to present the descriptive analysis of the results of a survey whose goal was to search for evidences of open innovation trends within the Brazilian aerospace cluster. The second goal is to answer, in an explorative basis, and based on the data from the same survey, the following two research questions:

- Does open innovation makes sense for companies of the aerospace industry in Brazil?

- How mature are companies in the cluster towards open innovation?

In other words, the goal behind this work is to verify whether collaborative and outsourcing activities within this industry are indeed part of an open business strategy or not, and where companies sit within the open innovation journey framework. This is an important issue to investigate, since most open innovation publications ignore the importance of business models to date (West and Bogers, 2013).

The relevance of this work lies on the previously mentioned lack of literature about open innovation in developing contexts. Moreover, there is a worldwide interest in Brazil since 2003, when Goldman Sachs issued a paper about the BRIC (Brazil-RussiaIndia-China) economies (Wilson and Purushothaman, 2003). One finds a number of publications which show evidences of openness within developing economy contexts, but there is no conclusive answer so far whether this issue should be managed in the same manner they are in developed countries.

Moreover, the open innovation literature lacks studies about more traditional high-technology segments, since most of the evidence found is from industries where innovation dynamics is more intense, such as the information and communications 
technology (ICT) and the pharmaceutical sectors. The aerospace industry is an example of such an industry for which one finds few studies discussing open innovation.

In order to fill both gaps, this paper presents the result of a research project which took place between 2011 and 2013 to investigate Brazilian aerospace companies in search of open innovation patterns within their R\&D and NPD strategies. This work's results and findings shall add to the current discussion concerning the dynamics of these "new entrants" in the global market.

The structure of the remainder of the article will present an overview of the Brazilian aerospace industry and its journey towards openness. Afterwards, the research methodology employed to investigate the subject is presented, which includes a conceptual model and the structuring of a survey followed by the main results and a descriptive and critical analysis of the data obtained from the survey will be presented. Finally, some conclusions will summarize this paper's contributions and makes suggestions for future investigation on the subject.

\section{THE BRAZILIAN AEROSPACE INDUSTRY AND ITS PATH TOWARDS RED OPENNESS}

A striking paradox in the Brazilian aerospace industry is that, although the country is proud to have Alberto Santos Dumont (1873-1932), a Brazilian-born inventor, among the pioneers of flight, the establishment of the industry has happened much later and did not occur spontaneously, but by means of government intervention. The creation of the Brazilian aerospace cluster in the city of São José dos Campos, strategically located in between São Paulo and Rio de Janeiro, the two largest metropolises in the country, is the cornerstone of the national aerospace. It was accomplished by the establishment, in the midtwentieth century, of the aeronautic research institute Centro Técnológico de Aeronáutica, nowadays called Departamento de Ciência e Tecnologia Aeroespacial (DCTA), and the Air-Forces engineering college Instituto Tecnológico de Aeronáutica (ITA) in the city (Ferreira, 2009; Gomes, 2012). Later on, in 1971, the establishment in the same city of the Brazilian space research institute (INPE - Instituto Nacional de Pesquisas Espaciais) consolidated São José dos Campos and surroundings as the heart of the aerospace cluster in Brazil. The history of most
Brazilian-owned aerospace companies is connected to these public institutes, as they are either spin-offs of these institutes, or have their founders coming from ITA, DCTA or INPE. That is the case of Embraer, Mectron and Avibras, to name a few.

Aerospace comprises three segments: aeronautics, defense and space (IMAP, 2011). Undoubtedly, the main segment within the Brazilian aerospace in terms of revenues is aeronautics, as shown in Fig. 1. This is mostly due to Embraer, a global leader in the regional jets segment. In 2007, for instance, the aeronautic segment was responsible for $92.9 \%$ of the total revenues in the Brazilian aerospace market, of which $84.5 \%$ is attributable to Embraer (Ferreira, 2009).

Not neglecting Embraer's importance to the cluster, one may not reduce the Brazilian aerospace industry to one single company. There are several other niche markets exploited by a number of different companies acting in the country that must be taken into account. One such niche market is the helicopter segment exploited by Helibras, a subsidiary of EADS Eurocopter, the only helicopter manufacturer in Latin America. There are also a number of smaller aircraft manufacturers that develop and produce smaller vessels for agriculture, flight training and leisure.

The defense and space segments in Brazil are highly segmented, with small and medium enterprises acting in very specific niche markets, related either to civil and military air control infrastructure, or to the modest but relevant Brazilian space program or yet to other initiatives that have the government as the demander and purchaser.

In all three segments, though, the role of the government is central for funding and supporting product development projects, beyond its role as purchaser and final user. Local authorities acknowledge this situation by considering the aerospace industry as a strategic segment for the national development plan (Gomes, 2012). Although strategic, throughout their history, aerospace companies often find a hard time regarding public support to develop their own technologies and products. This is partly

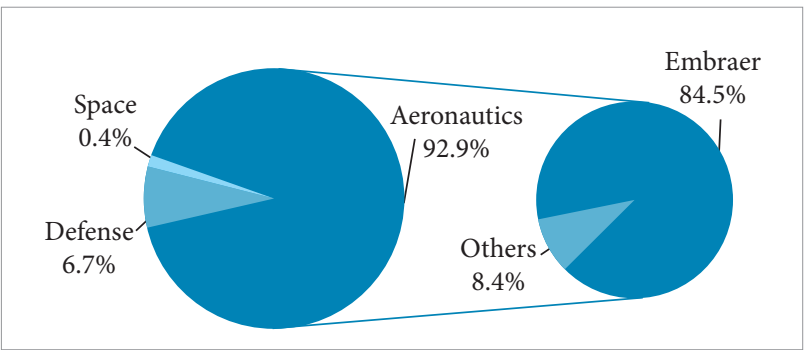

Figure 1. Brazilian aerospace market share in 2007 (Ferreira, 2009). 
due to the novelty of the regulatory framework for innovation in Brazil, whose cornerstone is the so-called 'innovation law' (federal law 10.973/04), issued only in 2004.

As a result, despite the country having a distinguished competence in this industry globally, the cluster is very dependent on foreign knowledge, even for the prime contractor Embraer. When analysing Embraer's supply chain, one realizes that $93 \%$ of its suppliers are located abroad due to the lack of qualification of local suppliers (Figueiredo et al., 2008). According to Cassiolato et al. (2002), the risk-sharing partnership model adopted by the company to develop its aircrafts since the mid-1990's was the solution Embraer found to gain access to the technology within the systems provided by its suppliers.

As for Helibras, since its establishment in the late 1970's, its business model was basically based on the manufacture and sale of aircrafts developed by its controller Eurocopter. More recently, though, the company is engaged with $R \& D$, thanks to some technology transfer agreements from Eurocopter, that put the Brazilian subsidiary in charge for the development of a couple of platforms. This R\&D is being performed in collaboration with local universities and public research institutes (Caiafa, 2012).

Finally, regarding the defense and space segments, the very structure of the market leads companies to collaboration, since their very small economies of scale and scope hinders them to invest in self-dependent $R \& D$ infrastructures. Collaboration is one of the few alternatives for survival in this scenario. One such example was the Atech-Omnisys joint venture for the development of the first 100\% national S-band weather radar, which resulted in the spin-off Atmos Systems (Silveira, 2005). Another example was Mectron's collaborative arrangement with Brazilian and South-African enterprises for the development of the fifth-generation missile A-Darter (Silveira, 2009).

Recently, these segments are attracting the interest of new and bigger entrants, such as the French company Thales, which controls the Brazilian firm Omnisys, since the acquisition of $51 \%$ of the company in 2005 (Mileski, 2011). Likewise, the Swedish company Saab started operations in Brazil, through the launch of R\&D facilities in 2011 (Pedroso, 2011), anticipating its victory in the fighter jet bid from the Brazilian Air Forces (Soto and Winter, 2013). Another important change in the segment's panorama was Mectron's acquisition by the Odebrecht group, the largest Brazilian company in the construction sector (Rolli, 2011).
All these recent changes motivated us to put forth the research project, which takes place within this dynamic environment, of alliances, partnerships, mergers and acquisitions, also characterized by secrecy and concealing due to the involvement of the military and matters of national sovereignty.

\section{METHOD}

The literature exploring the adoption of open innovation practices in aerospace is rather sparse and close to inexistent. Therefore, this work aims at performing an extensive investigation of open innovation concepts, tools, practices and strategies to verify what is in order for aerospace product development. To that purpose, we performed a questionnairebased survey covering all relevant aspects related to an open innovation strategy.

After gathering some information about the firm itself, the questionnaire inquires about technology innovation management in general (product and process innovation), using the OECD's Oslo Manual framework (OECD and EUROSTAT, 2005). The most extensive part of the questionnaire, though, is about open innovation issues. Departing from the tripartite division of open innovation proposed by Enkel et al. (2009), we elaborated a list of the pertinent issues associated to each core processes, presented in Table 1.

In order to analyze 'when' and 'how' open innovation occurs within product development process, we propose a conceptual model, based on the three-phased R\&D framework found in the Frascati manual (OECD, 2002). This model, presented in Fig. 2, identifies the internal "products" within the three activities of the $\mathrm{R} \& \mathrm{D}$ framework, that is, "knowledge" as basic research's main output, "technology” for applied research and "products" for development. The combination of such assets are the ideas, here defined as creative impulses, that allow the combination of existing data, information, knowledge and technologies into new knowledge, technologies, products and/or processes.

This conceptual model, along with the issues identified in Table 1, serve as a guide for the elaboration of an extensive survey questionnaire that structured the interviews performed during data collection.

Moreover, in order to cover for the open innovation journey, the questionnaire also inquires about open innovation culture 
(to evidence the "unfreezing" phase), formal business processes (for the "moving" phase) and open innovation metrics (for the “institutionalising" phase).

Table 1. Open innovation issues.

\begin{tabular}{|c|c|}
\hline $\begin{array}{c}\text { Core } \\
\text { process }\end{array}$ & Issues associated \\
\hline \multirow{5}{*}{ Outside-in } & External knowledge/technology sourcing \\
\hline & $\begin{array}{l}\text { Integration of the customer and/or user in the } \\
\text { innovation process }\end{array}$ \\
\hline & $\begin{array}{l}\text { Integration of the supplier in the innovation } \\
\text { process }\end{array}$ \\
\hline & Licensing in \\
\hline & Spin-ins, mergers and acquisitions (M\&A) \\
\hline \multirow{4}{*}{ Inside-out } & IP portfolio activity \\
\hline & Licensing out \\
\hline & Spin-offs and divestments \\
\hline & $\mathrm{R} \& \mathrm{D}$ outsourcing \\
\hline \multirow{3}{*}{ Coupled } & Co-development with other companies \\
\hline & $\begin{array}{l}\text { Collaboration with universities and other } \\
\text { science and technology institutes (STI) }\end{array}$ \\
\hline & Venture capital \\
\hline
\end{tabular}

The result is a very comprehensive questionnaire of 71 questions, which took in average one hour and a quarter to be filled out during interviews.

\section{RESULTS AND ANALYSES}

The survey sample comprises a total of 22 Brazilian aerospace companies that presented $\mathrm{R} \& \mathrm{D}$ activities and high degree of maturity in the product development process (Oliveira and Kaminski, 2012). These companies provided detailed information between the years 2007 and 2011 . Data collection was performed through personal interviews with R\&D managers or directors responsible for the innovation process management within the company. All interviews took place inside the participating companies.

The sample is representative of the population being studied. The official Brazilian aerospace catalogue CESAER (DCTA, 2011) comprises a list of 270 companies. However, when analyzing the catalogue, one realizes that this list includes companies that, although being part of the aerospace supply chain, are not indeed aerospace companies. After filtering out these

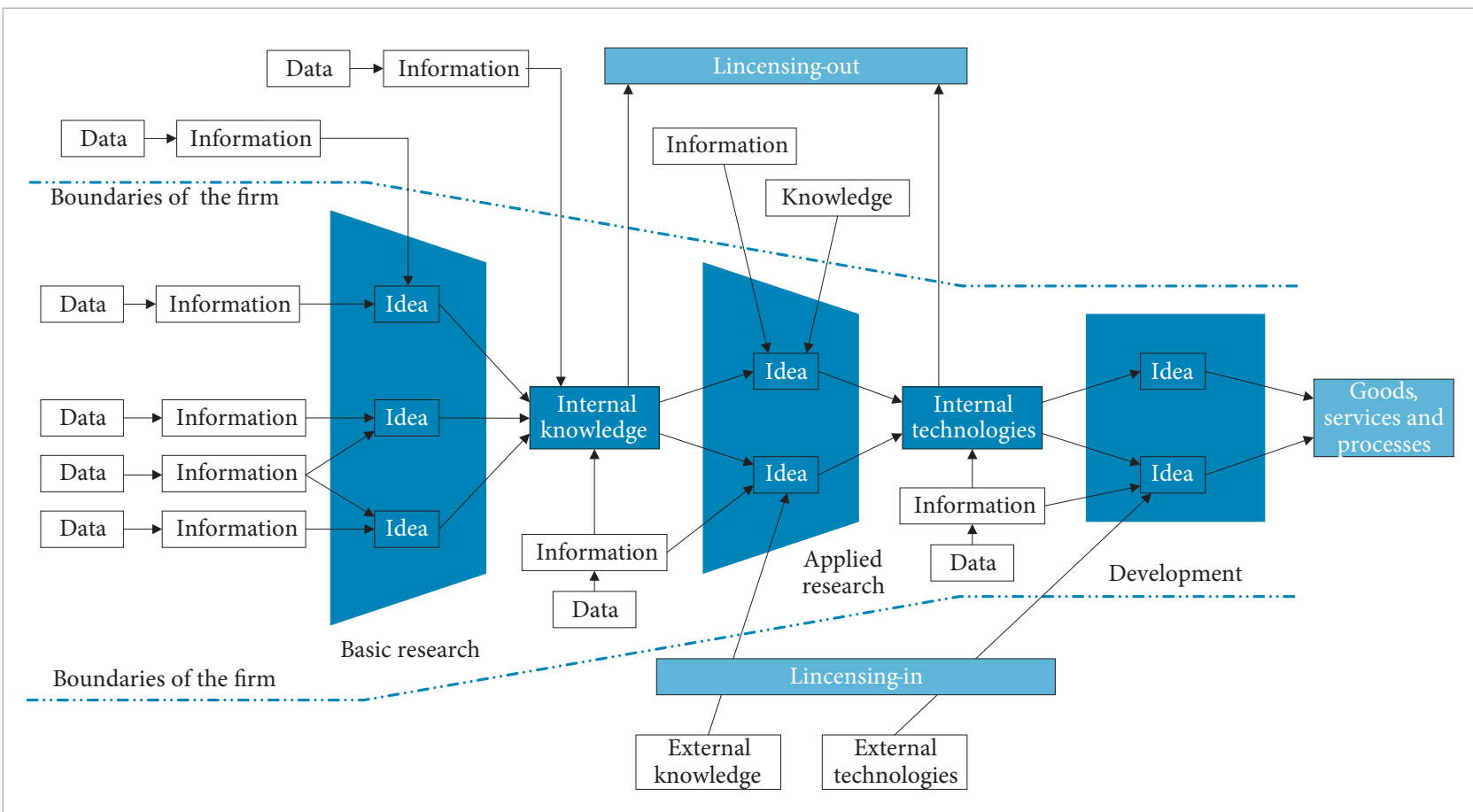

Figure 2. Open product-development conceptual model. 
companies, one finds 150 aerospace companies. The catalogue includes a brief description of each company's activities, which allows one to perform a second filtering, retaining only those engaged on R\&D activities. By doing so, only 59 firms are left in the population. Therefore, the sample obtained represents about $37 \%$ (22/59) of the population of interest for this study.

The aerospace industry comprises companies with varying technical expertise, since aerospace products embrace many different technologies. Looking up the distribution within the dataset, the largest proportion of firms lies in the electronic and avionic systems, followed by aircraft manufacturers/integrators and technical consulting firms. The others are specialized in satellite components, defense equipment, ICT/software, simulation equipment and mechanical machining. The small size of the population prevents us from disclosing the exact numbers of each category.

One can also cluster the according to the firm value chain position, among four possible options: prime contractors, equipment manufacturers, subcontractors and final users. This research does not target final users. Regarding the other three positions, Fig. 3 shows the distribution considering three scenarios: - The entire aerospace industry (150 companies);

- R\&D-engaged firms (59 firms); and

- This survey's sample (22 firms).

One realizes that the survey's subset oversamples the final links of the chain (prime contractors and equipment manufacturers), even when compared with the R\&D-engaged subset.

Turning now to size representativeness, in this study a firm is considered a Small and Medium Enterprise (SME) if it has 500 employees or less worldwide (that is, accounting all plants around the world). The distributions are shown in Fig. 4. Following the trend observed in the value-chain position analysis, the sample studied in the survey focuses on larger firms, when compared both to the whole industry population or to the share engaged with R\&D. Nevertheless, more than $3 / 4$ of the sample is composed of SMEs, which means that their position is undoubtedly captured in the analyses that follow.

\section{INNOVATION MANAGEMENT}

The first section after the introductory questions to the characterization of the sample focuses on traditional innovation management indicators, as established by the Oslo Manual (OECD and EUROSTAT, 2005). Although this manual distinguishes four different types of innovation (product, process, organizational

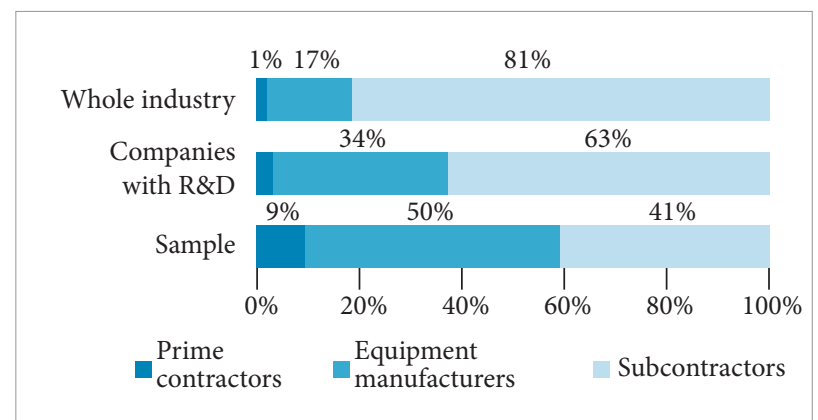

Figure 3. Firm distribution with respect to value chain position.

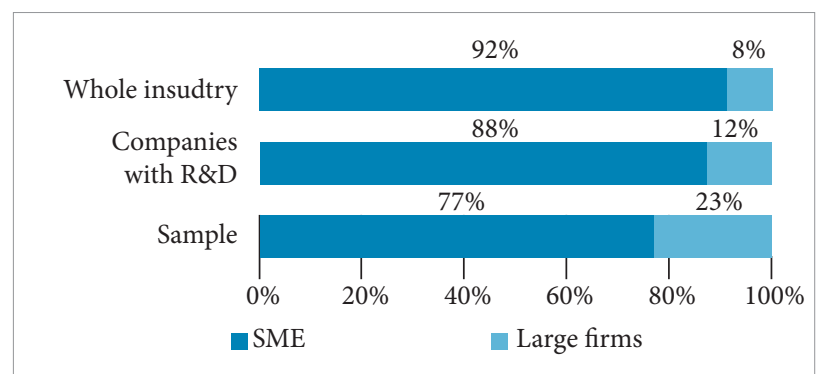

Figure 4. Distribution according to firm size.

and marketing), this survey concentrates only on technology product and process (TPP) innovation. All data covers the period ranging from 2007 to 2011.

As one can infer from Fig. 5, no single company claimed to be engaged only in process innovation, which indicates that innovation within this industry (or at least within the sample under analysis) is product-oriented. Figure 6 confirms this finding, by showing that the impact of product innovation tends to be higher when compared with that of process innovation. This corresponds exactly to what Pavitt (1984) defines as a science-based industry in the taxonomy he proposed in the 1980's.

Besides product and process innovation indicators, a common metric for innovation performance are intellectual property (IP) protection tools. Table 2 shows the percentage of companies within the survey sample that used IP protection tools in the 2007-2011 period: the proportion of firms using formal methods (e.g. patents) is low while strategic methods, such as secrecy and complexity of design, are more frequent in the sample. This result follows a Brazilian tendency, partly due to well-known shortcomings in patent registration in the country (Cruz and Mello, 2006; Gosain, 2013), in addition to a world-level low-patent tendency observed in the aerospace industry globally.

Moreover, Brazilian aerospace companies are in general not quite structured to deal with IP issues. As Fig. 7 shows, more 


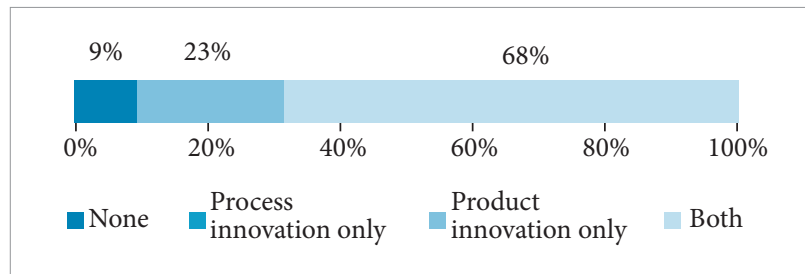

Figure 5. Types of innovation.

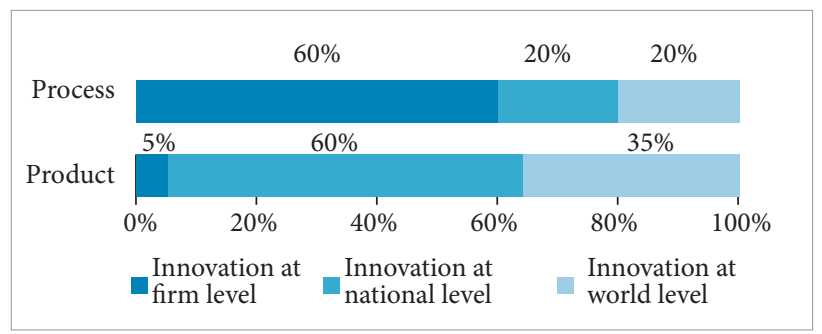

Figure 6. Highest innovation impact.

than 3/4 of the sample claimed either not to have any IP issues or to deal with them informally, when they occasionally occur. Only $28 \%$ of the respondents claimed to a formal structure to manage IP, and only half of it (14\%) within a Technology Transfer Office (TTO) or equivalent (9\% in the plant where the interview took place and 5\% in the firm, at a different plant).

Regarding at last the use of governmental support policies for innovation, Fig. 8 summarizes the adoption of a number of policies in the survey sample. The information that stands out is that more than half of the companies in the sample are users of non-refundable resources (grants) for innovation projects. Federal innovation agency FINEP and São Paulo state research agency FAPESP are the main culprits for this high rate, due to their well-established innovation support programs: "SubvençãoEconômica" from FINEP and "PIPE Pesquisa Inovadora na Pequena Empresa" from FAPESP, the latter addressed to small enterprises (with less than 250 employees).

As for the other indicators, the percentage is relatively low. This is partly due to the novelty of most programs, since they were in general established after the Brazilian innovation law, issued in 2004.

\section{PRODUCT DEVELOPMENT AND OPEN INNOVATION}

Recalling the conceptual model shown in Fig. 1, the questionnaire begins the open innovation section of the survey by inquiring where companies act across the R\&D spectrum. As expected, all companies in the survey claimed to be committed to development activities. About $2 / 3$ of the
Table 2. IP protection methods.

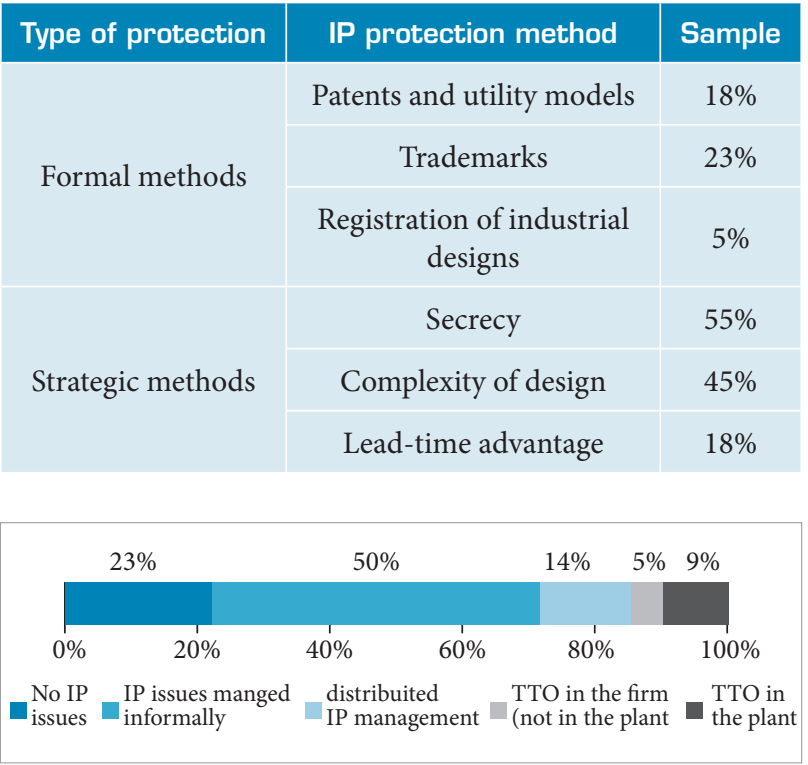

Figure 7. IP management.

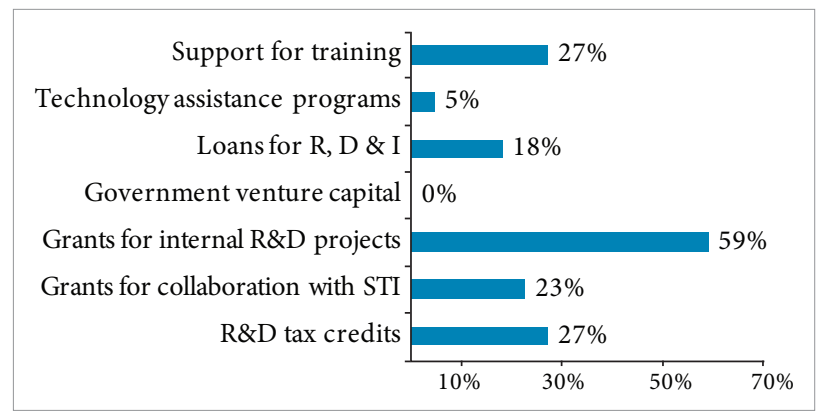

Figure 8. Use of innovation public policies.

sample claimed to perform applied research internally. As for basic research, only $9 \%$ of the companies claimed to perform such activities in Brazil and other 9\% claimed to perform it globally (in others plants) but not in Brazil.

In order to perform this $\mathrm{R} \& \mathrm{D}$, firms often find inspiration from others sources of knowledge. Figure 9 draws a radar diagram of the average importance attributed to a number of types of players that often contribute to R\&D. Since the number of samples that claimed to be engaged to basic research was very low, the radar comprises and compares only applied research with development. The importance was given through a sevenpoint Likert scale with no central point.

One can take interesting insights from the comparison between the two remaining shapes drawn in Fig. 9:

- Internal R\&D personnel are the most important, regardless of the $\mathrm{R} \& \mathrm{D}$ stage; 
- Firms from different industrial sectors are barely used as sources of knowledge for aerospace companies, regardless of the phase;

- Science and Technology Institutes (STI), such as universities and research labs are more important during research activities than for development;

- Industry players, especially clients and suppliers are of great importance during development, but less important during the research phase.

Among the same list, companies could name up to two players as the most useful for their respective R\&D. Figure 10 shows the frequency at which each player was mentioned.

Three players stand-out in this analysis: clients (59\%), universities (50\%) and suppliers (36\%). Interestingly, the option "firms from other industries" is a choice that no respondent made, which corroborates the low importance of cross-industry collaboration for the segment.

\section{OPEN INNOVATION STRATEGY}

As mentioned in the introductory part of this paper, a recent review paper on open innovation research (West and Bogers, 2013) observed that there is a tendency on open innovation research to neglect the importance of open business models and strategies, in spite of their importance to distinguish open innovation from earlier research on interorganizational collaboration in innovation. Opposing such tendency, this research dedicates a full set of questions to investigate how openness is connected to the firm strategy and their respective business models.

According to Dahlander and Gann (2010), there are two types of strategy for open innovation: pecuniary and nonpecuniary. Pecuniary strategies consist of external practices directly related to acquiring or selling companies, the first an inbound activity and the latter outbound. Figure 11 shows that a very low percentage of companies claimed to be engaged in this kind of practices in the 2007-2011 period, in both directions.

The low percentages may be attributed to the low importance of such practices inside aerospace companies' strategies, or may be due to the small time span of analysis (5 years). Merger and Acquisition (M\&A), spin-offs and divestments in most cases are not part of the ordinary agenda of companies, and their lead-time is often greater than other open innovation practices. In order to cover for that, the survey also inquired about former involvement of the plant in M\&A, divestment or spin-off processes, whose result is found in Fig. 12.

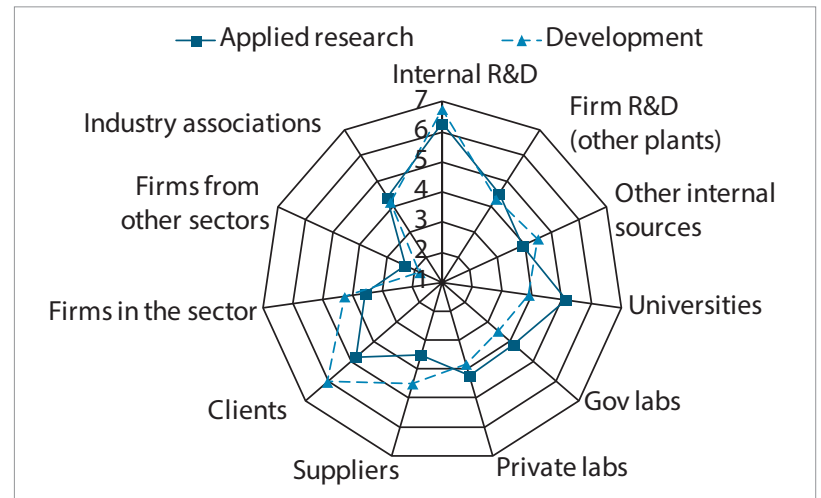

Figure 9. Importance of players as sources of knowledge for R\&D activities.

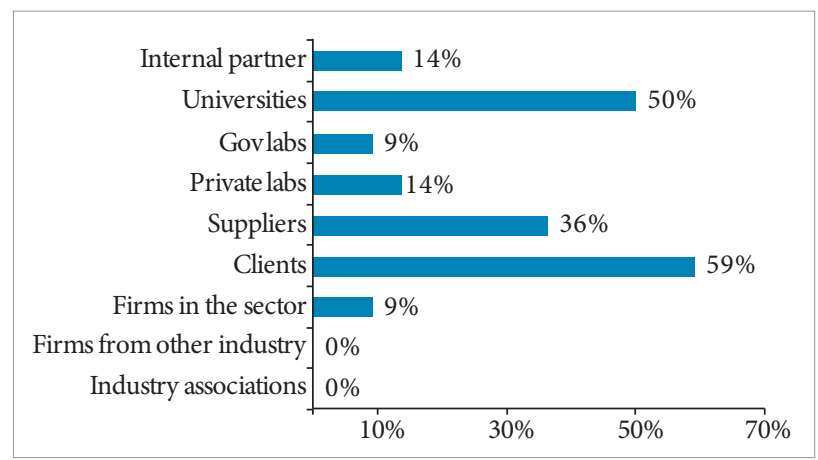

Figure 10. Top-of-mind partners for R\&D.

With that approach, we found a larger M\&A incidence within the sample. Therefore, even though $64 \%$ of the companies in the sample claimed they have never been involved with these matters, this result shows that this subject should not be disregarded when analyzing the Brazilian aerospace cluster, as $36 \%$ of the firms surveyed resulted from divestments, spin-offs or were merged or acquired by another company.

Turning now to non-pecuniary strategies, these are connected to sourcing (inbound) and revealing (outbound) practices (Dahlanderand and Gann, 2010). One first example of such strategy is licensing. Figure 13 shows the percentage of companies in the sample that claimed to have performed licensing during the 2007-2011 period.

The information that stands out is that not a single company in the sample claimed to have out-licensed their internal IP in this five-year period. In the inward direction, there were positive responses, but most of them are for the acquisition of specific development software tools or embedded software for the company's own products. Figure 14 indeed shows that a high percentage of licenses (70\% out of the $45 \%$ ) is due to software development firms. 


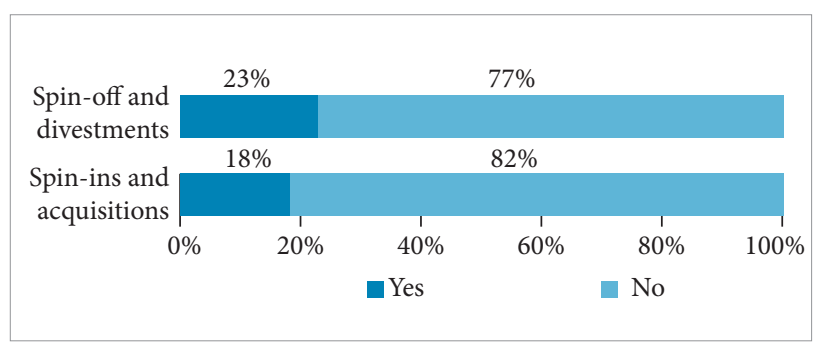

Figure 11. Strategic pecuniary practices related to the acquisition or selling of firms.

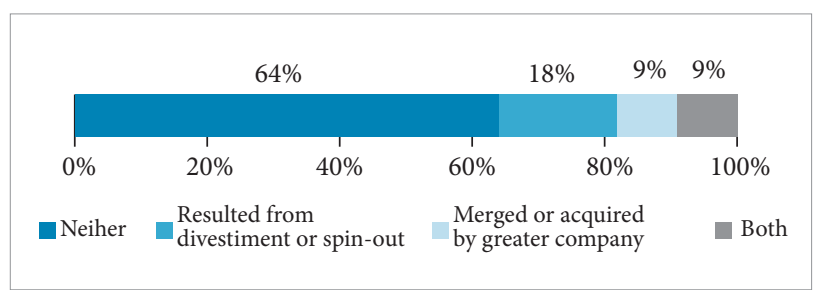

Figure 12. Plants previously involved in M\&A or divestment processes in the past.

When inquired about the importance of licensing activities for the company strategy, on a Likert-scale from 1 to 7 (where 1 means 'not important' and 7 means 'very important'), the average remained below 2 . Therefore, one concludes that firms in the sample do not adopt this kind of open strategy.

Another non-pecuniary revealing strategy is the provision of $R \& D$ services to third-parties. Now this is a practice that is found to be of great importance among surveyed firms. As Fig. 15 shows, roughly 3/4 (73\%) of the firms claimed to perform this kind of activity, and close to half (41\%) of them stated to perform this practice with great intensity.

The clients of these R\&D services (Fig. 16) are mostly local, or located within the country, with low international incidence, which indicates that collaboration takes place with firms' own networking links. Moreover, only $1 / 3$ of such services are provided within collaborative arrangements in a strict sense, the remaining $2 / 3$ are direct-contracted services for the development of parts for third-parties, in almost all cases, public institutes such as INPE, the DCTA or one of the many divisions of the Brazilian Air-Force Command (COMAER).

This kind of practice, performed through direct-contracted development services, show a poor adherence of the open innovation model to the modus operandi of these companies. First, they are not performing R\&D to develop their own products, but providing R\&D services for a living, by outsourcing their own technical expertises to third parties. Besides, this kind

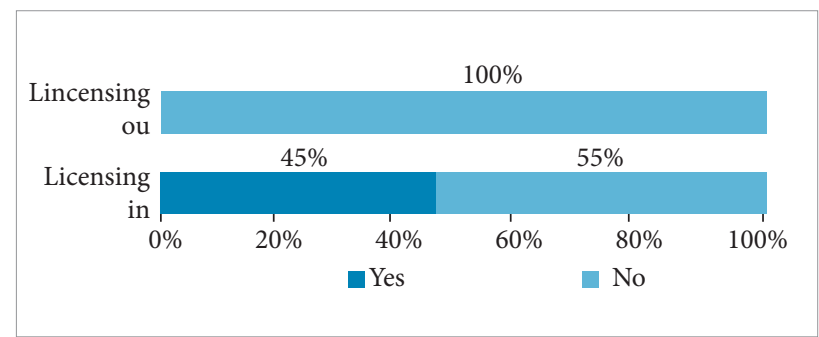

Figure 13. Licensing in and out.

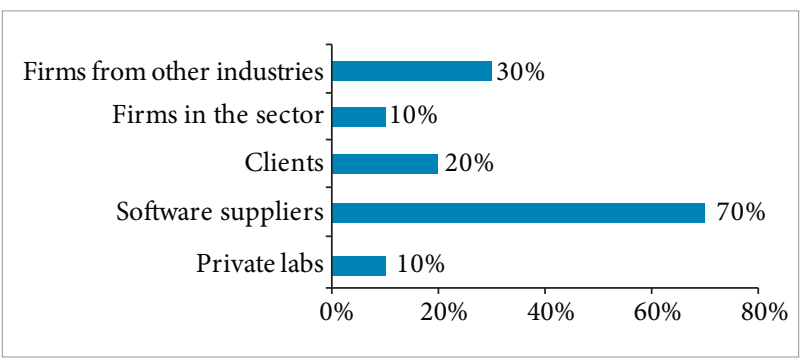

Figure 14. Type of organizations from which IP is licensed.

of collaboration cannot be considered a partnership in the strict sense of the word; it is more akin to a supplier-customer relationship. In addition, there is not an open business strategy behind the decision of balancing the disclosure and revealing of internal knowledge and technologies.

On the other hand, in line with Tranekjer and Knudsen (2012), the very provision of technical services to their customers grants these companies updated technical knowledge and privileged information about the market, which is crucial to their survival in the market, but also represents a source of opportunities to these companies to develop their own products. As a matter of fact, $68 \%$ of the R $\& D$ service providers in the sample claimed to use federal or state grants to finance the transformation of internal expertise into own products.

What differs from the findings of Tranekjer and Knudsen (2012) in Denmark is that Brazilian aerospace R\&D-service providers are not better product innovators in comparison to non-providers, since these firms often fail to accomplish the successful launching of such product innovations in the market. According to three $\mathrm{R} \& \mathrm{D}$-service providers in the sample, Brazilian authorities lack uniformity in their purchasing policies of aerospace technologies, which makes it difficult for local companies for profiting from their own NPD initiatives, since opportunities identified today may not be confirmed as a purchase order when the product is ready for deployment. 


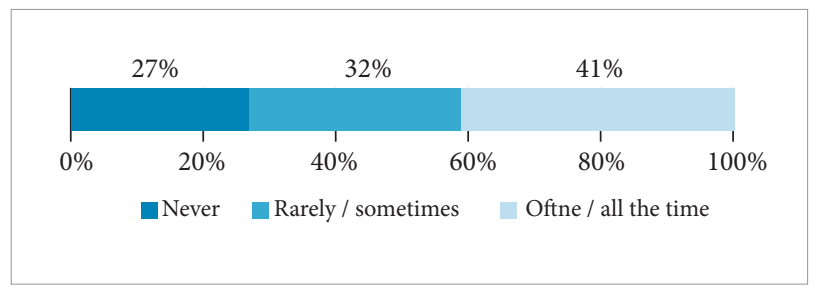

Figure 15. Proportion of firms providing R\&D services by frequency.

\section{OPEN INNOVATION CULTURE}

Even though open innovation may not be a reality in many aspects of Brazilian aerospace firms' behavior or strategy, its principles may yet be present in their internal culture. This is what Chiaroni et al. (2011) refer to as the "unfreezing" phase, which is addressed in the last part of the survey questionnaire.

By means of a series of questions about the importance the company accords to a number of aspects, the survey is able to identify which open innovation practices are more related to the company routine, and therefore to its culture. The cultural facet is an aspect that open innovation research papers often lack, according to West and Bogers (2013).

In Fig. 17, the level of importance attributed to each practice is shown in a 1-to-7 scale, since all questions were graded through a seven-point Likert scale (with no central point), and grouped by the three core processes (Enkel et al., 2009). As hinted from the results previously presented, there is a higher predominance of outside-in practices, followed by coupled activities and inside-out practices scored the lowest, with the exception of $R \& D$ services, as previously discussed.

Performing a simple average of the importance attributed to each practice within the three processes shown in Fig. 17, one obtains overall indices of 3.3 for outside-in, 2.6 for coupled and 2.0 for inside-out practices. Not surprisingly, outside-in scored highest, followed by coupled, and inside-out with the lowest score, which is consistent to a number of open innovation publications (OECD, 2008; Gassmann et al., 2010; West and Bogers, 2013) that assert that there is a dominance of the outside-in process over the others.

The final question to pose at this point is whether this scenario is consistent to a journey towards innovation openness. Since averages could be deceitful, one alternative is the creation of dummy variables to determine whether companies adopt each one of the three core-processes. To that effect, all three indices from all surveyed firms were put together, and the

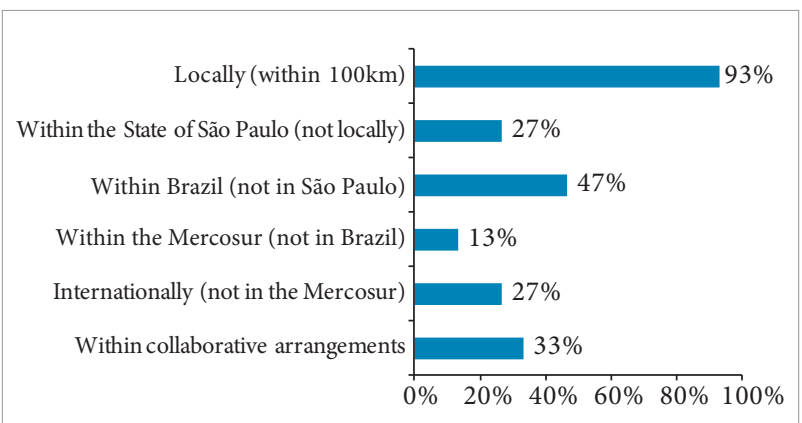

Figure 16. Location of R\&D service clients.

median value (found to be 2.7) was set as the threshold for determining whether a particular open innovation process is part of the culture for each participating firm. Afterwards, firms were grouped according to the processes that were found to be present at their respective cultures.

By doing so, it was found that there is a pattern of adoption of open innovation processes. A group of companies (about 28\% of the sample) was found not to adopt any of the three processes, which were labeled as "closed innovators". A second group of companies comprises those with one single process found within its culture (outside-in). This group corresponds to $5 \%$ of the sample. Among dual-process open innovators, two situations were found: outside-in is present in both cases, while the adoption of the second process differ: $14 \%$ of the sample adopts inside-out, while $43 \%$ of the companies, the largest group in this classification system, are coupled innovators. Finally, there is the full open innovators group that accounts for $10 \%$ of the sample, which adopt all three core processes. This classification system allows one the sketch the open innovation path illustrated in Fig. 18.

Outside-in is the first process to be incorporated into a firm's culture; pure inside-out or coupled innovators are inexistent in the sample. Companies only embody these core processes after they have mastered outside-in innovation. This finding is consistent to what Chiaroni et al. (2011) found in Italy.

With respect to the process of adoption of openness within the open innovation journey framework, this survey's questionnaire investigates the existence of a department formally responsible for open innovation processes and about the reference to open innovation activities in formal business process procedures of the firm. In both cases the incidence of positive answers was low (36\%), even though the questions were structured in order to find the slightest evidence of these rather than fully operational open innovation management.

The questionnaire also includes a few questions intended to verify whether "not-invented-here" (NIH) and the 
"not-sold-here" (NSH) syndromes (Chesbrough, 2003a) were present in the firm's culture. According to the responses provided during the interviews, we found a very low presence of these syndromes in Brazilian aerospace companies: NIH affects only $4.5 \%$ of the companies in the sample, and NSH $9.1 \%$. These answers clearly indicate a willingness to perform more collaboration and outsourcing than these firms actually do.

All these results allow one to conclude that open innovation is indeed present within these firms' culture, although not fully implemented in their strategies, internal procedures and market activity. It places the cluster in general in the "unfreezing" phase of the open innovation journey.

\section{CONCLUSIONS}

This paper aims to identify the level of integration of open innovation within the product development process.
Open innovation is an emergent mindset observed in some technology segments, the so-called open-dominated segments (Chesbrough and Appleyard, 2007). Within this new mindset, firms become increasingly aware of both external knowledge for using in internal technologies and markets, as well as external opportunities for the use of internal knowledge in different markets. The body of knowledge built in the specialized literature, though, is mostly based on the case studies within these opendominated segments, often within developed economies.

With that in mind, this research paper analyzed the applicability and relevance of open innovation within a different product development context in the Brazilian aerospace industry, a traditional high-tech industry within an emerging country. This industry is characterized by one large player (Embraer) and a large network of smaller companies, mostly concentrated in the cluster located in São José dos Campos and surroundings.

Through an extensive survey, this research was able to raise some interesting data to add to the open innovation

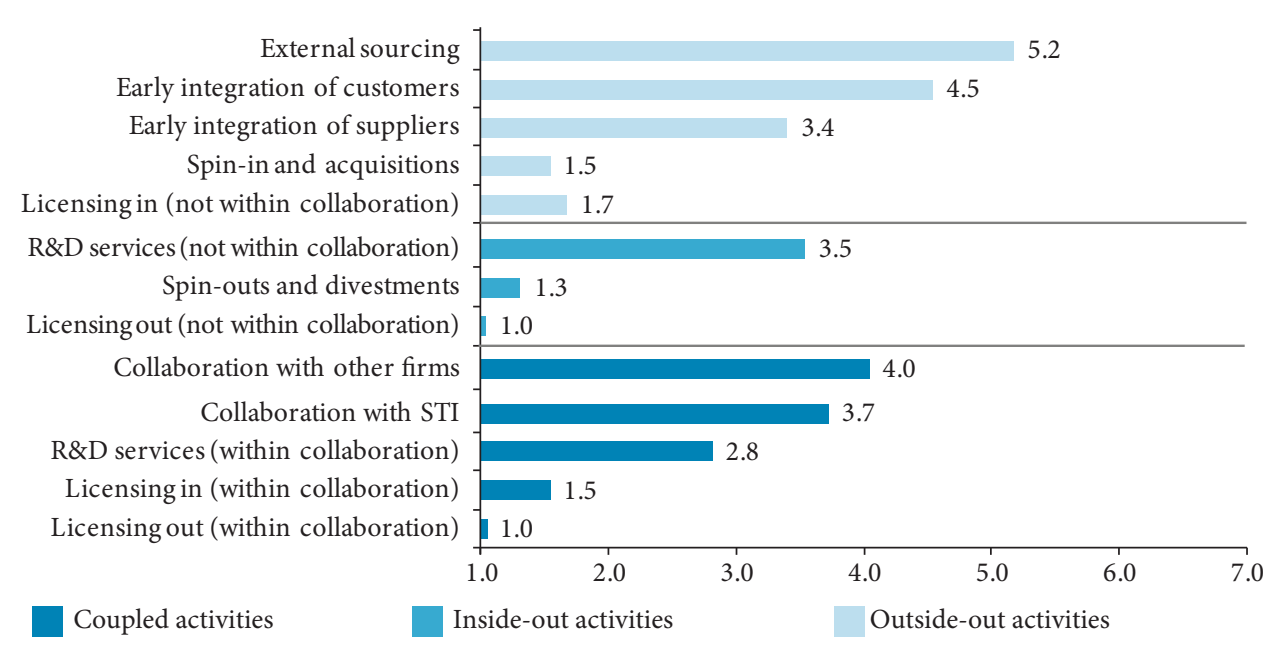

Figure 17. Open innovation practices as part of the day-by-day of Brazilian aerospace firms.

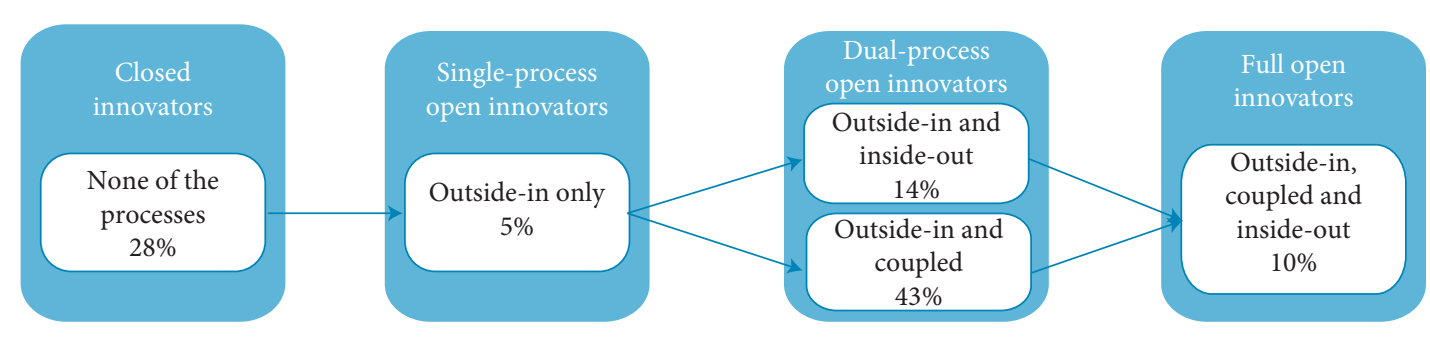

Figure 18. From closed to open: the journey of Brazilian aerospace firms. 
literature. This survey was performed by means of personal in-company interviews with 22 aerospace companies in the cluster, based on a questionnaire elaborated after the conceiving of a conceptual model to integrate open innovation to NPD, and a profound literature review for raising all pertinent issues within an open business strategy.

By means of traditional innovation metrics, based on the Oslo Manual (OECD and EUROSTAT, 2005), we have found in general a product-oriented low to medium innovative performance, with low IP management structuring, lowadoption of public innovation policies and local impact. The prominent relation is the supplier-customer relationship, followed by the collaboration with STI. The latter, though, is much more relevant during research activities in comparison to development phases.

Regarding, collaboration trends, we found that collaborative links are much more intense locally, and mostly with other aerospace companies. Besides, we found an awkward rate of $\mathrm{R} \& \mathrm{D}$ services provided through direct contract, which shows that many interviewed companies do collaborate, but not as a strategy for enhancing their own technologies and incomes, as advocates the open business model (Chesbrough, 2006; Chesbrough and Appleyard, 2007).

In short, these results seem to lead to the conclusion that collaboration in this industry follows traditional standards, and that it is not fully adherent to an open business strategy, as defined by Chesbrough and Appleyard (2007).

Analyzing the internal culture of the companies in the sample, though, we found that companies are willing to collaborate more and also to adopt more complex models for innovation and for sourcing and revealing outwards their own boundaries. However, institutional gaps in the Brazilian cluster prevent this willingness to become a reality. Among these gaps, the insight from some respondents point towards the lack of uniformity of the government in its role of purchaser and the prevention of companies from performing R\&D for the development of their own products, which in part is due to the first gap.

Comparing our findings to the open innovation journey framework proposed by Chiaroni et al. (2011), we found that the Brazilian aerospace cluster is indeed undergoing an openness process, but still in the "unfreezing" phase. In these stages, the sense of urgency for opening has been established, but institutional gaps prevents the clear adoption of an open business strategy. Through the analysis of the survey data, we can provide answers, on an exploratory basis, to the research questions formulated in the beginning of this paper. On the one hand, yes, open innovation does make sense in the Brazilian aerospace cluster; however, firms in the cluster do not seem to be very mature in dealing with open innovation, as they are in general still framed in the unfreezing phase of adoption of the new mindset.

Although this research focuses only one industrial segment (aerospace), from one single emerging economy country (Brazil), its results contribute for the general understanding of emerging economies in general, from an inductive perspective. The general panorama described in the data presented in this paper shows an industry with some very strong points from the knowledge and absorptive capacity perspective, but with structural gaps that prevents this potential to be fully developed. To change this scenario, effective government measurements are in order, to allow local companies to be able to develop their own technologies and products. For such, more than just offering funding alternatives, the government should revise its role as purchaser of aerospace technologies, and grant local companies a stable demand in the medium term that provides a stable ground for them to grow. On the other hand, there is also a step local companies should take, in order to organize further their R\&D structures, so that they reach higher NPD maturity, with less informalities and more consistent strategies. Currently, the industry sits on a vicious cycle, where companies do not invest in R\&D more because of lack of government support and the government do not support local companies because they lack R\&D structure.

As a final remark: one should be aware that all these results are based on a simple average of the results obtained from the interviews, accounted equally regardless of firms' income. If we performed weighted averages with respect to income, we would find a much different scenario, because one player (Embraer), if present in the sample, would overshadow the whole sample, which is a problem normally found in studies that analyze the Brazilian aerospace industry. It is a common mistake to assume that the Brazilian aerospace industry resumes to Embraer alone.The focus intended for this paper is precisely the opposite. Regardless of having Embraer in the sample or not, what we desired to analyze here was the reality of the industry as a whole, including the needs of all those small players normally neglected in business sectors analyses. 


\section{REFERENCES}

Brown, S.L. and Eisenhardt, K.M., 1995, "Product development: past research, present findings and future directions", Academy of Management Review, Vol. 20, No. 2, pp. 343-78. doi:10.2307/258850.

Caiafa, R., 2012, "R\$200 milhões em investimento: Centro Tecnológico de Helicópteros em Itajubá", Revista Tecnologia e Defesa, No. 130, São Paulo.

Cassiolato, J. E., Bernardes, R. and Lastres, H., 2002, "Innovation systems in the South: a case study of Embraer in Brazil", Paper prepared for UNCTAD-DITE investment policy and capacity-building branch, New York and Geneva, United Nations.

Chesbrough, H.W., 2003a, "Open innovation: the new imperative for creating and profiting from technology", Harvard Business School Press.

Chesbrough, H.W., 2003b, "The era of open innovation", MIT Sloan Management Review, Spring 2003, pp.35-41.

Chesbrough, H.W., 2006, "Open business models: how to thrive in the new innovation landscape", Harvard Business School Press.

Chesbrough, H.W. and Appleyard, M.M., 2007, "Open innovation and strategy", California Management Review, Vol. 50. No.1, pp. 57-76.

Chiaroni D., Chiesa, V. and Frattini, F., 2011, "The open innovation journey: how firms dynamically implement the emerging innovation management paradigm", Technovation, Vol.31, No. 1, pp. 34-43. doi: 10.1016/j. technovation.2009.08.007.

Cruz, C.H.B. and Mello, L., 2006, "Boosting innovation performance in Brazil", Economics Department Working Paper No. 532, Organization for Economic Co-operation and Development.

Dahlander, L. and Gann, D.M., 2010, "How open is innovation?", Research Policy, Vol. 39, No. 6, pp. 699-709. doi:10.1016/j.respol.2010.01.013.

DCTA, 2011, "CESAER: Catálogo de empresas do setor aeroespacial", Departamento de Ciência e Tecnologia Aeroespacial.

Enkel, E., Bell, J. and Hogenkamp. H., 2011, "Open innovation maturity framework", International Journal of Innovation Management, Vol. 15, No. 6, pp. 1161-89.

Enkel, E., Gassmann, O. and Chesbrough, H.W., 2009, "Open R\&D and open innovation: exploring the phenomenon", R\&D Management, Vol. 39, No. 4, pp. 311-16. doi: 10.1111/j.1467-9310.2009.00570.x.

Ferreira, M.J.B., 2009, "Perspectivas do investimento em ciência - documento setorial: aeroespacial \& defesa", Vol. 12, Projeto PIB, Universidade Federal do Rio de Janeiro (UFRJ)/ Universidade Estadual de Campinas (UNICAMP).

Figueiredo, P., Silveira, G. and Sbragia, R., 2008, "Risk sharing partnerships with suppliers: the case of Embraer", Journal of Technology Management and Innovation, Vol. 3, No. 1, pp. 27-27.

Freeman, C., 1991, "Networks of innovators: a synthesis of research issues", Research Policy, Vol. 20, No. 5, pp. 499-514. doi: 10.1016/0048-7333(91)90072-X.

Gassmann, O., Enkel, E. and Chesbrough, H.W., 2010, "The future of open innovation", R\&D Management, Vol. 40, No.3, pp.213-221.

Gomes, S.B.V., 2012, "A indústria aeronáutica no Brasil: evolução recente e perspectivas", in: Lage, F. (org.), "BNDES 60 anos: perspectivas setoriais", Banco Nacional do Desenvolvimento, Vol. 1, Ch. 4, pp. 139-185.

Gosain, R., 2013, "On the right track: the INPI ups its game", World Intellectual Property Review, May-June 2013, pp. 56-57.
IMAP, 2011, "Aerospace global report 2011", International Network of M\&A Partners.

Krishnan, V. and Ulrich, K.T., 2001, "Product development decisions: a review of the literature", Management Science, Vol. 47, No. 1, pp. 1-21. doi:10.1287/mnsc.47.1.1.10668.

Liyanage, S., Greenfield, P. and Don, R., 1999, "Towards a fourth generation R\&D management model - research networks in knowledge management", International Journal of Technology Management, Vol. 18, Nos. 3-4, pp.372-93.

Mileski, A.M., 2011, "O bom momento da Thales", Revista Tecnologia e Defesa, No. 123, São Paulo.

OECD, 2О०2, "Frascati manual - proposed standard practice for surveys on research and experimental development", Gth edition, Organization for Economic Co-operation and Development.

OECD, 2008, "Open innovation in global networks", Organization for Economic Co-operation and Development.

OECD and EUROSTAT, 2005, "Oslo manual: guidelines for collecting and interpreting innovation data", 3rd edition, Organization for Economic Cooperation and Development.

Oliveira, A.C. and Kaminski, P.C., 2012, "A reference model to determine the degree of maturity in the product development process of industrial SMEs", Technovation, Vol. 32, No. 12, pp. 671-80. doi:10.1016/j. technovation.2012.08.001.

Pavitt, K., 1984, "Patterns of technical change: towards a taxonomy and a theory", Research Policy, Vol. 13, No. 6, pp.343-73. doi:10.1016/00487333(84)90018-0.

Pedroso, R., 2011, "Governo quer transformar ABC paulista em polo da indústria de defesa", Valor Econômico, October 2Oth.

Rolli, C., 2011, "Odebrecht adquire controle da fabricante de mísseis Mectron", Folha de São Paulo, 25 March.

Silveira, V., 2005, "Atech constrói para SIVAM primeiro radar 100\% nacional", Gazeta Mercantil, 12 September, p.A-6, São Paulo.

Silveira, V., 2009, "Mectron fornece mísseis para o Paquistão", Valor Econômico, 17 April, p.B-9, São Paulo.

Soto, B. and Winter, B., 2013, "Saab wins Brazil jet deal after NSA spying sours Boeing bid", Reuters.

Tranekjer, T.L. and Knudsen, M.P., 2012, "The (unknown) providers to other firms' new product development: what's in it for them?", Journal of Product Innovation Management, Vol. 29, No. 6, pp. 986-99. doi:10.1111/j.1540-5885.2012.00974.x.

West, J. and Bogers, M., 2013, "Leveraging external sources of innovation: a review of research on open innovation", Journal of Product Innovation Management, Vol. 31, No. 4, pp. 814-831. doi:10.1111/ jpim. 12125.

West, J., Vanhaverbeke, W. and Chesbrough, H.W., 2006, "Open innovation: a research agenda", in: Chesbrough, H.W., Vanhaverbeke, W. and West, J. (eds.), 2006, "Open innovation: researching a new paradigm", Oxford University Press, Ch.14, pp. 285-307.

Wilson, D. and Purushothaman, R., 2003, "Dreaming with BRICs: the path to 2050", Goldman Sachs Global Economics Paper No: 99. 